\title{
Research
}

\section{Source/Sink Patterns of Disturbance and Cross-Scale Mismatches in a Panarchy of Social-Ecological Landscapes}

\author{
$\underline{\text { Nicola Zaccarelli }}^{1}, \underline{\text { Irene Petrosillo }}^{1}{ }^{1}$ Giovanni Zurlini $^{1}{ }^{\text {, and Kurt Hans Riitters }}{ }^{2}$
}

\begin{abstract}
Land-use change is one of the major factors affecting global environmental change and represents a primary human effect on natural systems. Taking into account the scales and patterns of human land uses as source/sink disturbance systems, we describe a framework to characterize and interpret the spatial patterns of disturbances along a continuum of scales in a panarchy of nested jurisdictional socialecological landscapes (SELs) like region, provinces, and counties. We detect and quantify those scales through the patterns of disturbance relative to land use/land cover exhibited on satellite imagery over a 4yr period in the Apulia region, South Italy. By using moving windows to measure composition (amount) and spatial configuration (contagion) of disturbance, we identify multiscale disturbance source/sink trajectories in the pattern metric space defined by composition and configuration of disturbance. We group disturbance trajectories along a continuum of scales for each location (pixel) according to broad land-use classes for each SEL level in the panarchy to identify spatial scales and geographical regions where disturbance is more or less concentrated in space indicating disturbance sources, sinks, and mismatches. We also group locations by clustering, and results are compared in the same pattern space and interpreted with respect to disturbance trajectories derived from random, multifractal and hierarchical neutral models. We show that in the real geographical world spatial mismatches of disturbances can occur at particular scale ranges because of cross scale disparities in land uses for the amount and contagion of disturbance, leading to more or less exacerbation of contrasting source/sink systems along certain scale domains. All cross-scale source/sink issues can produce both negative and positive effects on the scales above and below their levels, i.e., cross-scale effects. Through the framework outlined in our examples, managers, as well as stakeholders belonging to SELs in the panarchy, can be aware of specific scale ranges of disturbance where mismatches might occur and that will help them to value where and how to intervene in the panarchy of SELs to enhance the benefits and to minimize negative effects.
\end{abstract}

Key Words: disturbance mismatches; disturbance source/sink; multiscale disturbance patterns; panarchy; social-ecological landscapes.

\section{INTRODUCTION}

Land-use change is one of the major factors affecting global environmental change and represents a primary human effect on natural systems, and underlying fragmentation and habitat loss, which are the greatest threats to biodiversity (Alcamo and Bennett 2003). Since human land use is a major force in driving landscape change, landscape dynamics can be better understood in the context of complex adaptive socioeconomic and ecological systems (e.g., Berkes and Folke 1998), integrating phenomena across multiple scales of space, time and organizational complexity. In the real geographic world such systems can be better defined as social-ecological landscapes (SELs), taking into account the scales and patterns of human land use as ecosystem disturbances.

During recent decades, worldwide losses of biodiversity have occurred on an unprecedented scale and agricultural intensification has been indicated as a major driver of this global change (e. g., Matson et al. 1997, Donald et al. 2001, Tilman et al. 2002, Stokstad 2006). Agricultural intensification is determined by practices on both local and landscape scales (e.g., Matson et al. 1997, Tilman et al. 2002). On a local scale, it is due to 
shorter crop rotation cycles, decreased crop diversity, increased input of mineral fertilizers and pesticides, winter sowing of cereals, implementation of genetically modified (GM) crops, and monoculture, increased field size, and machinedriven farming. On a landscape scale, intensification occurs owing to conversion of perennial habitat into arable fields, destruction of hedgerows, fragmentation of natural habitat, the loss of low-intensity land-use management, reallocation of land to increased field size, loss of set-aside fallows, cultivation of formerly abandoned areas, and farmer specialization in one or few crop types.

Land-use intensification has disrupted ecological processes such as biological pest control (e.g., Matson et al. 1997, Tylianakis et al. 2004) and crop pollination (e.g., Stokstad 2006). Increased fertilizer inputs can reduce water quality (e.g., Vitousek et al. 1997), decrease the richness of plant species (e.g., Mitchell et al. 2004) and increase the occurrence of plant diseases (e.g., Vickery et al. 2001). Local landscape intensification may affect grassland production (e.g., Loreau and Hector 2001), and resistance to plant invasion (e.g., Kennedy et al. 2002). Recent agricultural intensification also includes GM crops, which offer new opportunities for increased yields in the coming decades, but also risk side-effects (Hails 2002). Also the dynamic spatial configuration of land use in SELs resulting from human appropriation can have a variety of ecological effects at a landscape scale. Fields have been merged and enlarged to enhance farming efficiency resulting in homogeneously farmed landscapes. New land-cover types can be juxtaposed within increasingly fragmented native land-cover types, modifying nutrient transport (Peterjohn and Correll 1984), affecting species persistence and biodiversity (Tilman et al. 2002, Benton et al. 2003), and nurturing invasive species (With 2002).

Disturbances are deemed as any relatively discrete event in space and time that disrupts ecosystem, community, or population structure and changes resources, substrates, or the physical environment (Pickett and White 1985). In this study land-use intensification is deemed as a disturbance from a landscape perspective which is justifiable in the context of SELs, since observed land-use/landcover changes demonstrate that agricultural fields are more dynamic than other types of land-use systems (e.g., Young and Harris 2005). This standpoint is different from classical land-cover mapping that would ignore, for instance, apparent disturbances from crop rotation because agricultural fields can be fallow one year and planted the next, and still be labeled as agricultural fields. In addition, drawing on the notion of source and sink coined for metapopulation by Levins (1969), agricultural fields with their widespread practices might act as a source or a sink as to the potential spread of disturbance agents like fire, pesticides, fertilizers, pests, diseases, and alien species to neighboring nonagricultural areas, along with a variety of potential associated ecological effects at the landscape scale. In summary, the effects of land-use intensity on local biodiversity and ecological functioning in SELs depend on spatial scales much larger than a single field or land use. This demands a landscape perspective, which takes into account the spatial arrangement of surrounding land-use types at multiple scales (Turner and Gardner 1991, Ricketts 2001).

Anthropogenic disturbances are determined by the social component of SELs organized in a panarchy of nested jurisdictional levels defined as clearly bounded and organized social-political units, e.g., household, village, county, province, region, and nation (Cash et al. 2006). This draws on the notion of hierarchies of influences between embedded scales, and how these linked scales influence each other and cross-scale effects can take place (Gunderson and Holling 2002). In social-ecological landscapes (Berkes and Folke 1998) such crossscale mismatches become so critical that spatial effects are expected when the spatial scales of management and the spatial scales of ecosystem processes do not align properly leading to inefficiencies, and/or loss of important components of the ecological system and, ultimately, to disruptions of SELs (Cash et al. 2006). In Europe, social and ecological systems are so interlinked that any SEL is bound to be anyhow disturbed to some degree (Reidsma et al. 2006). Then if disturbance patterns originating from various land-use managements do not follow the same pathway across scales, scale mismatches can take place owing to disparities of disturbance among land uses across scales in the landscape that can exacerbate or mitigate the contrast between disturbance sources and sinks at particular scale ranges.

Although social-ecological systems and panarchy are becoming a popular topic of inquiry in ecology (Carpenter and Turner 2001), it is surprising that little theoretical or practical work has explicitly 
addressed frameworks able to indicate the scaling behavior of human disturbances in a real panarchy of SELs. In this study, rooted in previous results on both real disturbance patterns (Zurlini et al. 2006) and simulated neutral landscape pattern maps (Zurlini et al. 2007), we develop a conceptual framework and apply it through the state space of the disturbance pattern, i.e., composition and configuration, for both simulated and real landscapes in a panarchy of SELs, i.e., region, provinces, counties, in Apulia, southern Italy. Unlike our previous studies, we set few broad landuse/land-cover categories with their relevant disturbances as the thematic base level for the whole panarchy of SELs. Our intention is to analyze and interpret SELs along a continuum of scales through patterns of disturbance trajectories relative to landuse/land-cover to indicate spatial pattern domains of disturbances and mismatches. To this purpose, we produce a disturbance map based on satellite imagery of Apulia, and employ moving windows (Milne 1992) to measure composition (amount) and configuration (contagion) of disturbance patterns. We obtain disturbance trajectories at multiple scales for each location (pixel), and we group locations according to broad classes of land-use and membership for each subregion in the panarchy. We also group locations by clustering, and results are compared in the same state space, identified by composition and configuration of disturbance, to the clustering from simulated random, multifractal and hierarchical neutral maps. We then indicate the spatial scales and SELs where disturbance is more or less concentrated in space along the panarchy indicating disturbance sources, sinks, and mismatches.

\section{MATERIALS AND METHODS}

In order to better communicate our methods, we have constructed an Appendix as a tutorial for the reader on satellite imagery and processing, normalized difference vegetation index (NDVI), change detection, moving windows and neutral landscape models (NLMs), as well as further details which have received thorough treatment elsewhere (Zurlini et al. 2006, 2007).

\section{Study area}

Apulia is an administrative region of $1,936,000$ ha in southern Italy, inhabited for thousands of years, mostly karstic with a typical semi-arid Mediterranean climate with hot and dry summers and moderately cold and rainy winter seasons (Viel and Zurlini 1986). For our purposes, Apulia can be visualized as a panarchy of nested jurisdictional levels of social-ecological landscapes (region, provinces, and counties) embodying different sets of political, social, economic, and cultural features (Fig. 1). All hierarchical levels can be described in terms of their unique social-ecological landscapes (SELs) based on the composition of land-use.

Overall, more than $82 \%$ of Apulia contains agroecosystems (see the Appendix for further details). To provide a realistic interpretation of spatial properties of Apulia landscapes, we reclassified the original Corine land-cover map of Apulia (APAT 2005; Fig. 1) into four broad land-use/land-cover categories (Table 1), namely arable land, heterogeneous agricultural areas, permanent cultivations, which are mostly olive groves, and natural areas including forests and shrub and/or herbaceous associations. We consider only landuse/land-cover classes of the terrestrial surface, which total $100 \%$ (Table 1), excluding seawater, lagoons, wetlands, and urban and industrial areas.

\section{Change detection and what is meant by disturbance}

We use satellite change detection to produce a map of disturbance as input to the analysis of disturbance patterns. Six cloud-free Landsat Thematic Mapper 5 (TM) and two Enhanced Thematic Mapper Plus (ETM+) images with a 30-m pixel resolution in the same period of vegetation phenological cycles in two different years, i.e. June 1997 and June 2001, have been processed to describe the pattern of change in Apulia (see the Appendix). As change response variable, we use changes over time in NDVI, defined as the difference between the visible (red) and near-infrared (nir) bands, over their sum (Goward et al. 1991). NDVI has been validated as a robust indicator of vegetation photosynthesis, with built-in relationships to social-ecological processes such as habitat conversion or crop rotation, and related to a number of vegetation indicators and characteristics (see Young and Harris 2005, and 
Fig. 1. Panarchy of nested jurisdictional levels defined as clearly bounded and organized jurisdictional units in Apulia, an administrative region of 1,936,000 ha in south Italy. Three main jurisdictional levels can be identified (region, province, county): one unit for the region, five units for the province level, and 258 units for the county level. The entire region or each sub-unit in the panarchy can be described in terms of their unique social-ecological landscapes (SEL) based on land-use composition. Six broad landuse/land-cover classes (top) and a simplified example of Corine land-cover map for one county (down) are presented. The original Corine land-cover map (1:100.000) updated at 1999 has a global accuracy of $88.1 \%$ and a Cohen's K coefficient of 0.84 (APAT 2005). Our use of broader land-use/land-cover categories improves upon that classification accuracy.

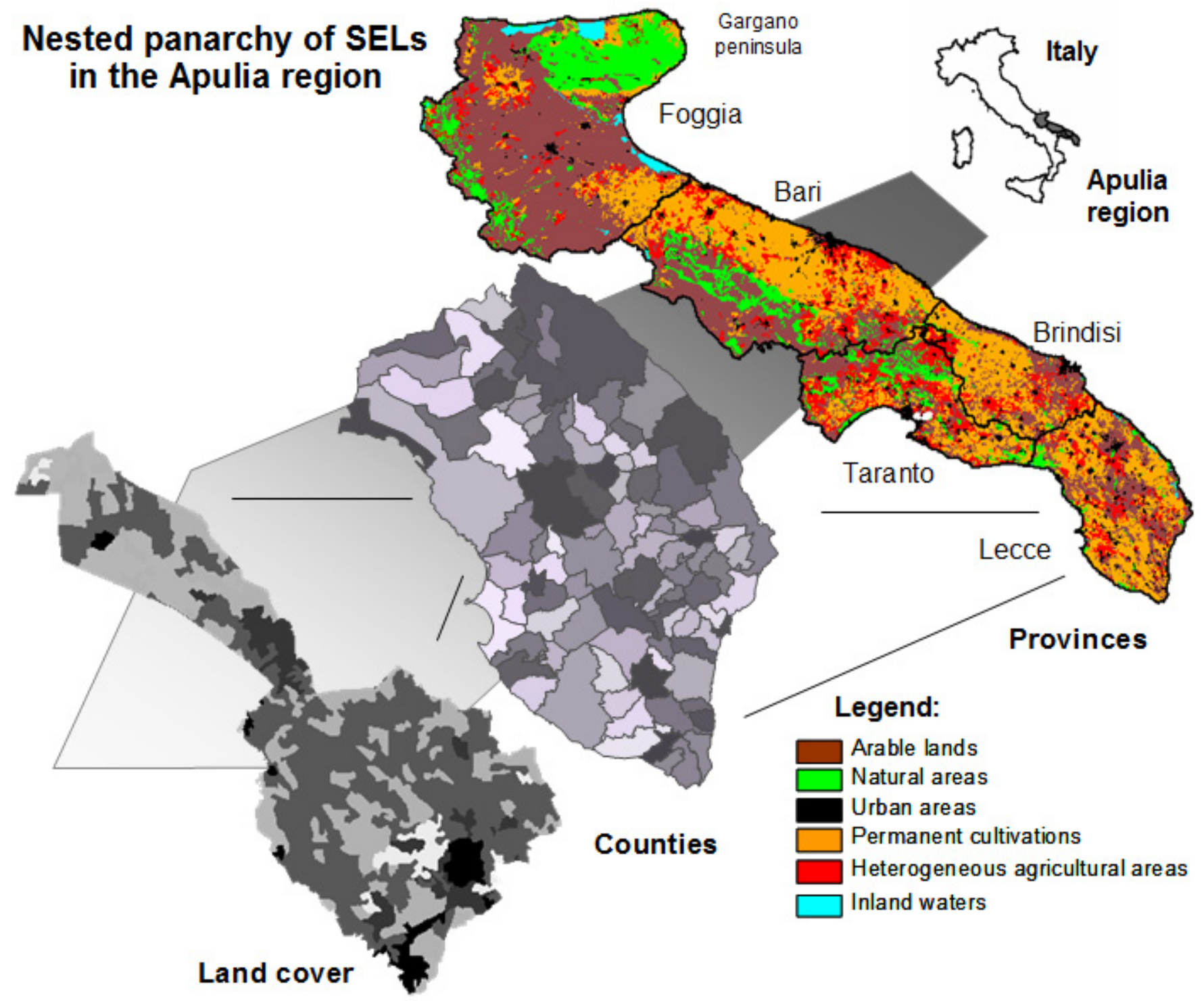


Table 1. Broad land-use/land-cover categories of Apulia and its five nested administrative provinces, based on the aggregation of Corine classes from 1999 land-use/land-cover map (see text). Percentages sum up to $100 \%$ and are calculated only for terrestrial surface by excluding seawater, lagoons, wetlands and urban fabrics (adapted from Zurlini et al. 2006).

\begin{tabular}{lcccccc}
\hline \hline & \multicolumn{7}{c}{ Percentage composition } \\
\hline Category & Apulia & Bari & Brindisi & Foggia & Lecce & Taranto \\
Arable lands & 41.7 & 30.9 & 28.6 & 59.2 & 35.0 & 30.2 \\
Permanent cultivations & 30.2 & 40.7 & 53.5 & 11.7 & 48.0 & 25.5 \\
Heterogeneous agricultural areas & 13.8 & 16.9 & 15.3 & 7.3 & 13.3 & 26.4 \\
Natural areas & 14.2 & 11.5 & 2.5 & 21.8 & 3.8 & 17.9 \\
& & & & & & \\
\hline
\end{tabular}

references therein). In addition to this evidence, we wanted to substantiate the sensitivity of NDVI to vegetation changes for the Apulia region, before it was used further for change detection (see the Appendix).

Since landscape mosaic is mostly defined by vegetation cover, we operationally measure disturbance by any detectable alteration in land cover reflecting significant and relatively frequent NDVI changes, mainly assignable to fast humandriven disturbances (CEC 1999), as captured by a narrow four-year time window (see the Appendix). We focus on land cover dynamics including both NDVI gains and losses, so that disturbances are mostly associated with agricultural expansion and intensification, conversion of perennial habitats and vineyards to field cultivation and new olive grove tillage, farming practices such as fire and crop rotation, and urban sprawl. It is worth noting that, in this context, disturbance might also be due to afforestation, which is the conversion of open land into a forest by planting seeds or trees as it widely occurs in Apulia for new olive grove tillage promoted by EU subsidies. Large disturbances from windstorms, floods, and fires are extremely rare in the region and did not occur within the temporal window of this study.

In summary, taking into account the different sources of error, we believe that it is possible by this procedure to capture most of the significant real human-driven disturbances detectable at the resolution of Landsat imagery. However, there might be cases where occasionally NDVI does not capture disturbance when it is in fact there, for example in agricultural fields which went from one crop to the same or another crop but retained exactly the same NDVI. On the contrary, it would be very unlikely that this procedure captures disturbance when it is not there.

\section{The conceptual framework of disturbance patterns at multiple scales}

To analyze spatial patterns it has been suggested that it is best to focus on a few key measures (Li and Reynolds 1994, Riitters et al. 1995) and, for categorical map data, on the two fundamental components of a pattern, namely composition, i.e., the quantities of various entities, and configuration, i.e., their spatial arrangements (Li and Reynolds 1994, Fortin et al. 2003). In our case, the entity is defined as disturbance and we therefore characterize landscape patterns in terms of the amount and spatial arrangement of disturbance.

Consider a binary map showing pixels of disturbed and undisturbed locations. Multi-scale disturbance patterns can be measured and mapped using an overlapping pixel-level moving window whereby scale is varied by changing the size of the window (Milne 1992, Kerkhoff et al. 2000). Within a given 
window, composition is expressed as the probability of disturbance, and is estimated by the proportion of pixels that are disturbed $\left(P_{d}\right)$. Configuration is measured within the same given window by the adjacency of disturbance, given by the probability that a disturbed pixel is adjacent, by the fourneighbor rule, to another disturbed pixel $\left(P_{d d}\right)$, so that it is a measure of contagion. For any given location, the trends of disturbance composition and configuration over window size describe the local spatial pattern of disturbance surrounding that location (Milne 1992). Taken together, composition and configuration can describe a wide range of spatial patterns that are encountered on real maps (Riitters et al. 2000, Zurlini et al. 2006, 2007). Mapping composition and configuration reveals geographic variation and/or coherence in the local spatial patterns of disturbances, so that they can be used to define a state space of pattern $\left[P_{d}, P_{d d}\right]$ that further describes disturbance patterns (Fig. 2). Two places occupying the same region of the state space experience the same pattern of disturbance at that scale. In addition, the multiscale disturbance trajectory can be visualized as a trajectory in the same state space. For the purpose of comparison, multiple scale trajectories for eight clusters (C1-C8) of disturbance composition for the Apulia region are presented for two thresholds of change (see the Appendix $)$, either $10 \%$ or $20 \%\left(P_{d}=0.1\right.$ and $P_{d}=0.2$ respectively), for the same temporal window 19972001 showing rather similar patterns (Fig. 2). Places near the upper left hand corner have relatively higher disturbances with a low degree of spatial autocorrelation, whereas places near the lower right hand corner have lower disturbances but are much more clumped within the window. Overall, Apulia turns out to experience relatively low disturbances, since $84.9 \%$ of Apulia locations are grouped by the four least disturbed clusters $(\mathrm{C} 1-\mathrm{C} 4)$ at $P_{d}=0.1$, and $75.4 \%$ at $P_{d}=0.2$ (Fig. 2).

\section{Exercising the framework: disturbance patterns in a panarchy of social-ecological landscapes}

A critical component of our conceptual framework is the convergence point, labeled $\mathrm{CP}$, in Fig. 2, which represents the $\left[P_{d}, P_{d d}\right]$ value for the ideal window exactly equal in size to the entire geographic region of a given SEL within the panarchy. In principle, each location (pixel) could have a unique disturbance trajectory of up to the $\mathrm{CP}$ value of the entire region. All trajectories must converge on the $\mathrm{CP}$ as the window size approaches the size of the SEL. In this study we are interested in grouping locations according to a few broad landuse classes for each subregion in the panarchy (Table 1). This approach is different from Zurlini et al. (2006, 2007) who clustered all locations independently of land use (Fig. 2). For any given location (pixel), the trajectories of disturbance composition and configuration over window size describe the local spatial pattern of the disturbance surrounding that location at multiple scales (Milne 1992). For example, a small window with high disturbance composition combined with a large window with low disturbance composition implies a higher local disturbance (potential source) embedded in a larger region of lower disturbance (potential sink). Different trends for two different locations imply differences in spatial trajectories of disturbance leading to mismatches.

Once a region is chosen, i.e., Apulia in our case, to define the overall upper limit of the panarchy with its disturbance composition (i.e. $P_{d}=0.10$, the threshold value we fixed to define disturbed pixels), one can go down the hierarchy so that the trajectories of disturbance composition and configuration over window size for subregions (SELs) can be derived and compared on the same $\left[P_{d}, P_{d d}\right]$ space by their relative $\mathrm{CP}$ values and disturbance trajectories within and across hierarchical levels in the panarchy (see the Appendix). We apply the moving window algorithm to the disturbance map, with ten window sizes, in pixel units, spanning from 0.81 to 4556.3 ha (see the Appendix). For the cut-off of subregions, subregional trajectories cannot be derived directly from those of higher levels in the hierarchy, thus composition and configuration measurements must be taken separately for each subregion. As a result, at regional level composition and configuration encompass provinces and counties, whereas at provincial level their values encompass only counties. Finally, we compare SEL convergence points and the different shapes of trajectories, and look back to the geographical space to evaluate the physical locations of pixels and interpret the meaning of disturbance trajectories in terms of realworld locations. 
Fig. 2. Pattern state space $\left[\mathrm{P}_{\mathrm{d}}, \mathrm{P}_{\mathrm{dd}}\right]$ defined by composition $\left(\mathrm{P}_{\mathrm{d}}\right)$ and configuration $\left(\mathrm{P}_{\mathrm{dd}}\right)$ and disturbance trajectories at multiple scales (10 window sizes) for eight clusters $(\mathrm{C} 1-\mathrm{C} 8)$ representing disturbance patterns in Apulia in the period 1997-2001. On top, the two figures correspond to an overall $\mathrm{P}_{\mathrm{d}}=0.10$, $\mathrm{i}$. e., disturbance of $10 \%$ (left), and $\mathrm{P}_{\mathrm{d}}=0.20$, i.e., disturbance of $20 \%$ (right) respectively, with $\mathrm{P}_{\mathrm{dd}}$ in both cases about 0.41 . The percentage of pixels belonging to each cluster is given in the legend. All trajectories converge from the finest to the coarsest scale, i.e., from smallest to largest window size, on a regional point called convergence point $(\mathrm{CP})$. Below, the single trajectories of $\mathrm{P}_{\mathrm{d}}$ and $\mathrm{P}_{\mathrm{dd}}$ vs. scale (10 window sizes) are shown (see text; adapted from Zurlini et al. 2006, 2007).
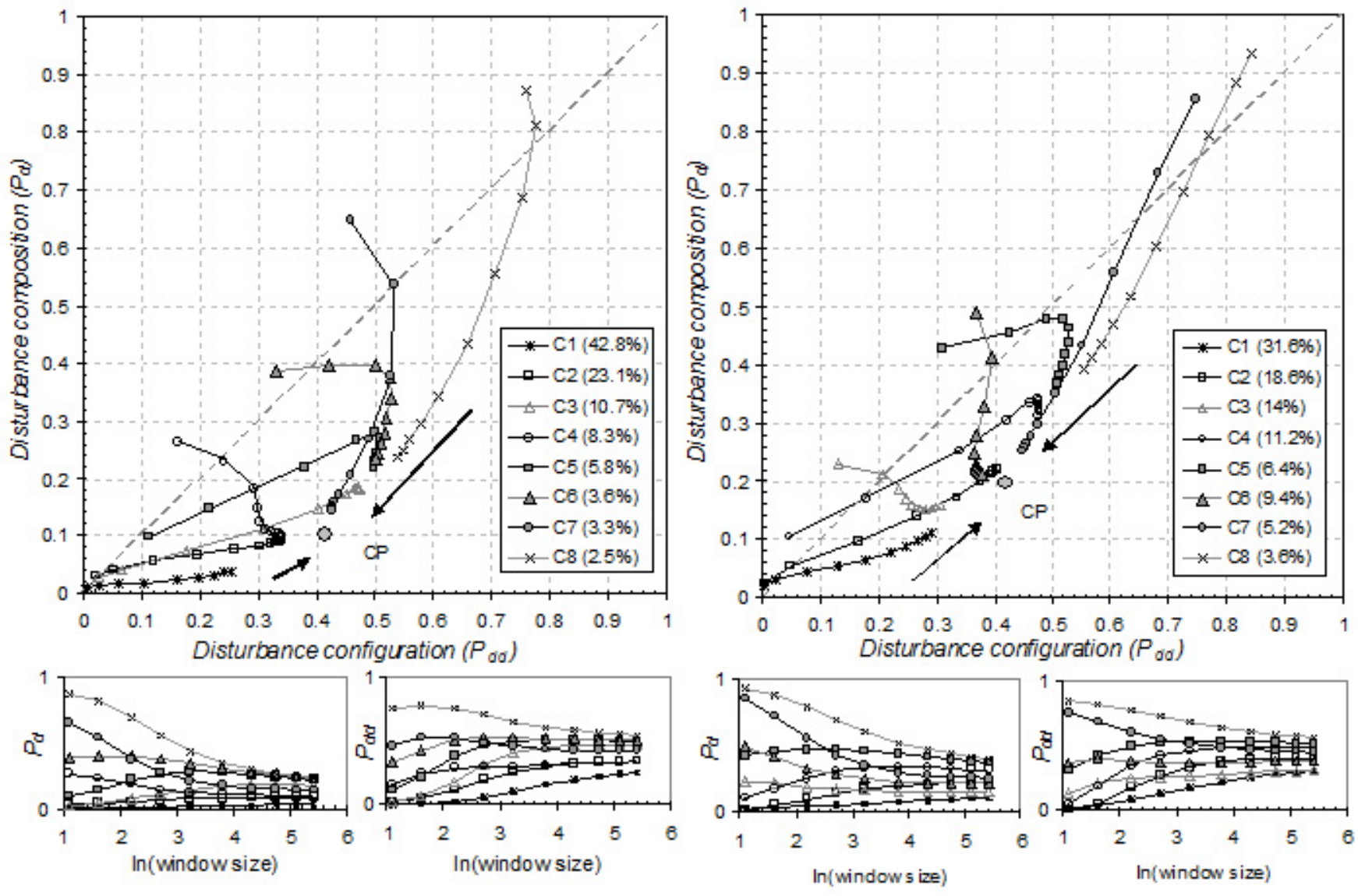

\section{Disturbance sources or sinks}

Any region in the panarchy is characterized by the spatial composition (what and how much is there) and configuration (how is it spatially arranged) of landscape elements like land use/land cover. Any landscape element, in turn, contributes to the overall proportion of disturbed pixels $\left(P_{d}\right)$ in the region, through its composition of disturbed locations (pixels). In rural landscapes, elements with higher land cover dynamics (disturbance) like fields characterized by widespread agricultural practices, might act as a source of the potential spread of disturbance agents like fire, pesticides, fertilizers, pests, diseases, and alien species to neighboring nonagricultural areas (sink). Such interplay of exchange of disturbance agents among land uses or regions in the panarchy can conveniently draw on the notions of source and sink adopted by Levins (1969) to describe a model of metapopulation dynamics of insect pests in agricultural fields. Thus a landscape perspective of disturbance source-sink 
patterns is ultimately required to evaluate how changes in landscape structure, e.g., habitat fragmentation, may affect the potential spread of disturbance agents.

Disturbance trajectories at multiple scales on the $\left[P_{d}, P_{d d}\right]$ state space, indicate whether and where land-use disturbances might act as a potential source or as a sink. If a mean trajectory is always larger than the $\mathrm{CP}$ of reference and tends downwards to the $\mathrm{CP}$, then land-use disturbances act as a source because there is a locally high rate of disturbance embedded in a larger region of fewer disturbances. Otherwise, land-use disturbance acts as a sink because there is a locally low rate of disturbance embedded in a larger region of heavy disturbances. Disturbance source effects are expected to be greater not only in terms of higher composition of disturbance $\left(P_{d}\right)$ but also in terms of higher configuration of disturbance $\left(P_{d d}\right)$.

To compare CPs by their disturbance composition $\left(P_{d}\right)$ and configuration $\left(P_{d d}\right)$ (proportions) we use log-odds ratios (Agresti 1996) (see the Appendix). The larger the log-odds, the greater will be the difference. When proportions are respectively equal, the log-odds ratio is 0 otherwise, they can be positive or negative. If they are positive, e.g. for disturbance composition, SEL acts in general as a source of disturbance respect of the SEL of reference, on the contrary SEL acts as a sink.

\section{Generating neutral landscape patterns}

Simulated, neutral landscape models have evolved from simple random landscape maps (Gardner et al. 1987) to maps with hierarchical structure (O'Neill et al. 1992, Lavorel et al. 1993). To compare disturbance trajectories from clustering (Fig. 2) to NLMs, we generated simulated random, multifractal and hierarchical landscape pattern maps. Details of procedures and results are given in the Appendix.

\section{RESULTS}

\section{Upper jurisdictional level (region)}

In the $\left[P_{d}, P_{d d}\right]$ space defined by composition and configuration of disturbance, land-use trajectories for the regional level have been found to be almost aligned along the configuration axis $\left(P_{d d}\right)$ and remain largely unvaried as to composition $\left(P_{d}\right)$ across the ten window sizes (scales) converging to the regional $\mathrm{CP}$ only at the largest windows (Fig. 3 ). They appear ordered according to increasing disturbance composition in a precise sequence. Thus, arable land (41.7\% of Apulia in Table 1) can act as a disturbance source in the range of scales considered, showing composition and configuration levels higher than those of other land uses. Heterogeneous agricultural areas $(13.8 \%)$ show an intermediate trajectory at about the same disturbance level of regional $\mathrm{CP}$, with a very fine texture, followed by permanent cultivations (30.2\%) and natural areas (14.2\%) with the two lowest trajectories indicating their possible sink role. Initial disturbance configurations of trajectories show an increase from natural areas to arable lands. Arable land trajectory very nearly converges with the $\mathrm{CP}\left(P_{d d}=0.417\right)$, whereas for other land uses there are gaps between the highest window size $(6.75 \mathrm{~km}$ lag distance $)$ and the regional CP. Gaps depend on both the initial configuration value and cross-scale increase of configuration comprised within the ten windows. The differences between the final and initial disturbance configurations $\left(\Delta P_{d d}\right)$, over the highest spatial (linear) lag distance $(6.75 \mathrm{~km})$ provide a measure of the average linear rate of increase of disturbance configuration across scales for each land use (Fig. $3)$. Taking into account the fact that initial disturbance configuration $\left(P_{d d}\right)$ level for arable lands is more than twice that of natural areas, arable lands show relatively higher cross-scale linear increments with an outstanding average increment $\left(\Delta P_{d d} \mathrm{~km}^{-1}\right)$ of $=0.127$ in the first $2.25 \mathrm{~km}$ of lag distance $(75 \times 75$ window size in pixel units), whereas other land uses show similar but lower and more equally distributed increments. Such differences give an indication of spatial cross-scale mismatches among land uses as to their accumulative rate of disturbance clumping across scales.

\section{First nested jurisdictional levels (provinces)}

In the same $\left[P_{d}, P_{d d}\right]$ space of Fig. 3, disturbance trajectories of the different land uses in different provinces again align mainly along the $P_{d d}$ axis (Fig. 4 ), while the relevant CPs of social-ecological landscapes (SELs) in space show a clear sequence at increasing $P_{d d}$ from Lecce (bottom left) to Foggia (upper left, Fig. 4). Diversity among processes and regimes of disturbance emerge more clearly at this 
Fig. 3. Disturbance trajectories for the four broad land-use classes of Apulia at multiple scales (10 window sizes) at regional $\mathrm{P}_{\mathrm{d}}=0.10$ are represented in the same state space $\left[\mathrm{P}_{d}, \mathrm{P}_{\mathrm{dd}}\right]$ of Fig. 2. Initial $\mathrm{P}_{\mathrm{dd}}$ values, cross-scale linear increments $\left(\Delta \mathrm{P}_{\mathrm{dd}} \mathrm{km}^{-1}\right)$ of disturbance configuration (in bold) for each land-use disturbance trajectory, and regional convergence point (black dot) are shown. Dashed lines attempt to connect identical window sizes among different land uses to exemplify cross-scale disturbance mismatches, e.g., between arable lands and natural areas.

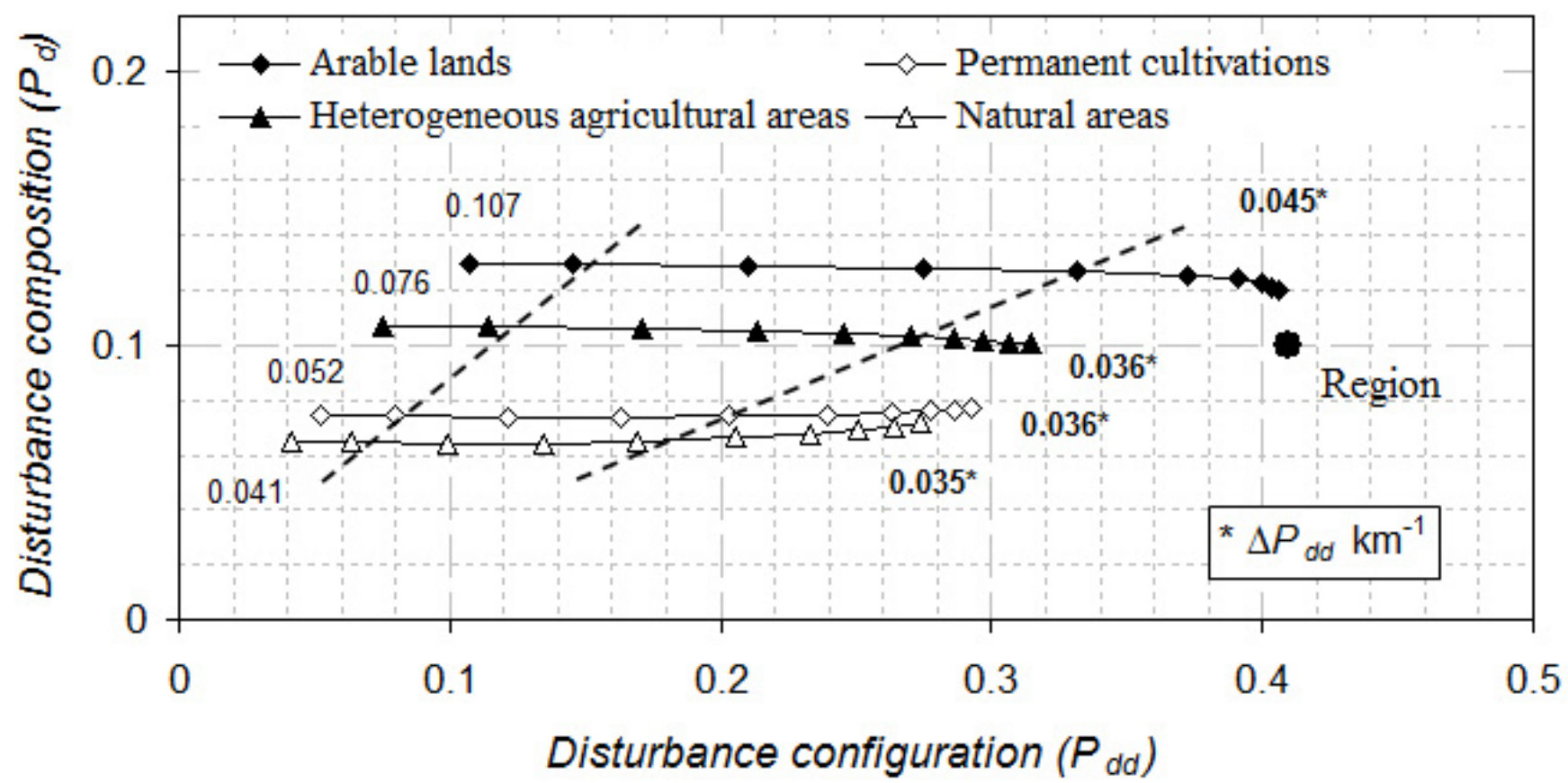

lower hierarchical level, and differences among land-use classes appear within the same province, as well as among provinces with the same land-use class (Fig. 4). The sequence of land-use trajectories, e.g. going from lower to higher disturbances is not always the same for the five provinces, nor is the sequence of province trajectories within the same land-use class (Fig. 3). Foggia shows a sequence of trajectories in the $\left[P_{d}, P_{d d}\right]$ space similar to that of the all region.

The different land-use trajectories are related to the different source/sink role played by each land use in a province with respect to the same land use in other provinces. The spread of land-use trajectories for Foggia is much wider than that at the regional level or in other provinces both for composition (maximum $P_{d}$ around 0.19 ) and configuration (maximum $P_{d d}$ about 0.51 ) leading to rather contrasting source/sink systems. On the other hand,
Lecce, Taranto, and Bari show less diverse trajectories meaning less contrasting source/sink systems. Disturbance trajectory for arable land in Foggia (59\% of its area, Table 1) is completely different from the other locations as it shows a much higher disturbance composition and tends to its $\mathrm{CP}$ at scales with lag distance of about $1.3 \mathrm{~km}$. This identifies it as a clear disturbance source much higher than that of other provinces (Fig. 4).

Permanent cultivation trajectories vary from province to province. However, disturbance appears prevalently to have an external source as trajectories, with the exception of Taranto and Bari, are generally lower than the relevant CP. Brindisi, in particular, shows the lowest trajectory in the range of scales sampled. Accordingly, natural areas generally play a role of sink, and for Foggia they show very low disturbances because of the presence of the Gargano Peninsula, which includes a large 
Fig. 4. Land-use disturbance trajectories at multiple scales (10 window sizes) for the five provinces of Apulia at regional $P_{d}=0.10$, and relative convergence points (CPs) are shown in the same state space $\left[\mathrm{P}_{\mathrm{d}}, \mathrm{P}_{\mathrm{dd}}\right]$ of Fig. 2, and 3. The CP (black dot) for the entire Apulia region is shown for comparison (see text).
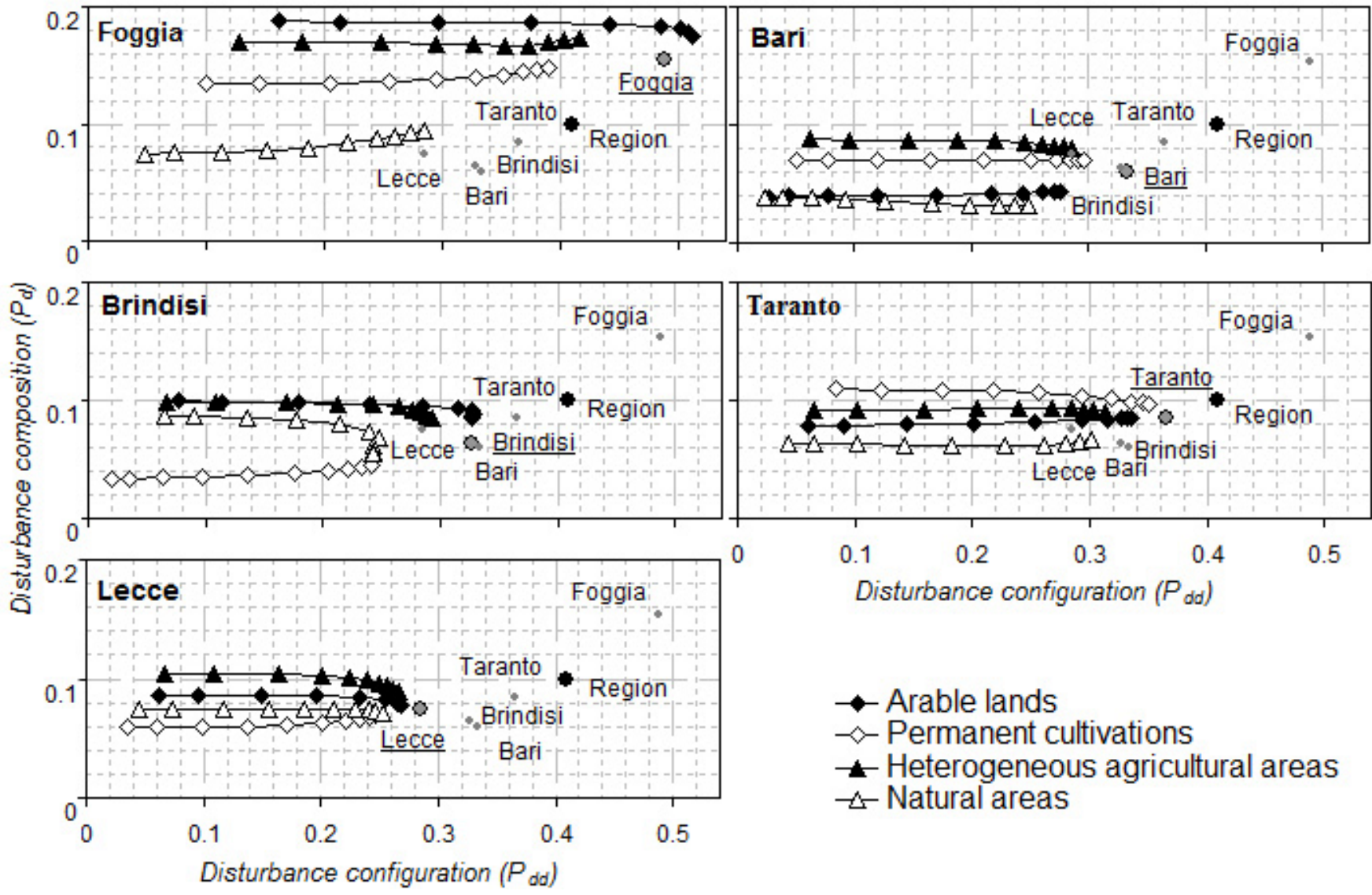

$\prec$ Permanent cultivations

$\_$Heterogeneous agricultural areas

$\triangle$ Natural areas

protected area. The exception is Brindisi where natural area trajectory stands at a slightly higher composition than the pertinent $\mathrm{CP}$, i.e., it acts as a source up to a lag distance of about $2.2 \mathrm{~km}$, then composition drops suddenly to those of the permanent cultivation trajectory (sink) (Fig. 4). Such switches from source to sink along scales also create mismatches with the trajectories of other land uses.

\section{Second nested jurisdictional level (counties)}

Given the exceedingly high number of counties present in Apulia (i.e., 258), we consider for illustrative purposes the two most dissimilar counties out of the 97 , which make up the province of Lecce (Fig. 5) with their land-use trajectories in $\left[P_{d}, P_{d d}\right]$ space. Salice Salentino shows disturbance $\left(P_{d}=0.171\right)$ on average much higher than that of the region; arable land is a clear disturbance source, followed by permanent cultivations (vineyards), and by heterogeneous agricultural areas, both sinks. Natural area trajectories have lower disturbances (sink) reaching up to the CP. Salice Salentino has a $\mathrm{CP}$ much higher than the region indicating an overall high disturbance regime, while Salve shows disturbance on average much lower $\left(P_{d}=0.036\right)$ than the entire region. A particular disturbance sequence occurs, with heterogeneous agricultural areas acting as source, then natural areas and arable land. Permanent cultivations such as olive groves and natural areas act as sinks. 
Fig. 5. Land-use disturbance trajectories at multiple scales (10 window sizes) for two counties (second nested jurisdictional level) of Apulia at regional $\mathrm{P}_{\mathrm{d}}=0.10$, i.e., Salice Salentino and Salve in the province of Lecce (small map in the center). On top, maps of land use with disturbed locations in black. Land-use percentage composition (bottom left), and disturbance trajectories for land-uses (bottom right) in the same state space $\left[\mathrm{P}_{\mathrm{d}}, \mathrm{P}_{\mathrm{dd}}\right]$ of Figg. 2, 3, and 4, with the pertinent CPs and the CPs of the upper hierarchical levels of the panarchy, i.e., Lecce province and region (see text).

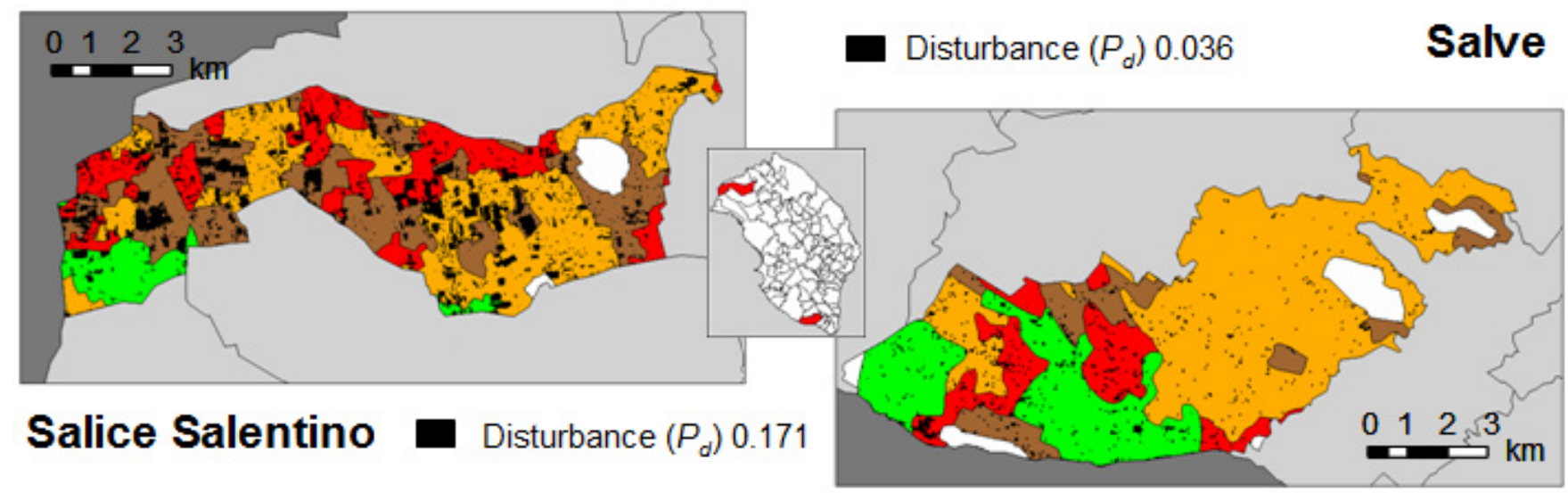

\begin{tabular}{lrr}
\hline $\begin{array}{c}\text { Land-cover } \\
\text { class }\end{array}$ & $\begin{array}{r}\text { Salice } \\
\text { Salentino } \\
(\%)\end{array}$ & $\begin{array}{r}\text { Salve } \\
(\%)\end{array}$ \\
\hline $\begin{array}{l}\text { Arable lands } \\
\text { Permanent } \\
\text { cultivations }\end{array}$ & 30.0 & 9.7 \\
$\begin{array}{l}\text { Heterogeneous } \\
\text { agricultural }\end{array}$ & 39.8 & 51.9 \\
$\begin{array}{l}\text { areas } \\
\text { Natural areas }-\end{array}$ & 20.2 & 12.1 \\
Urban areas \\
\hline
\end{tabular}

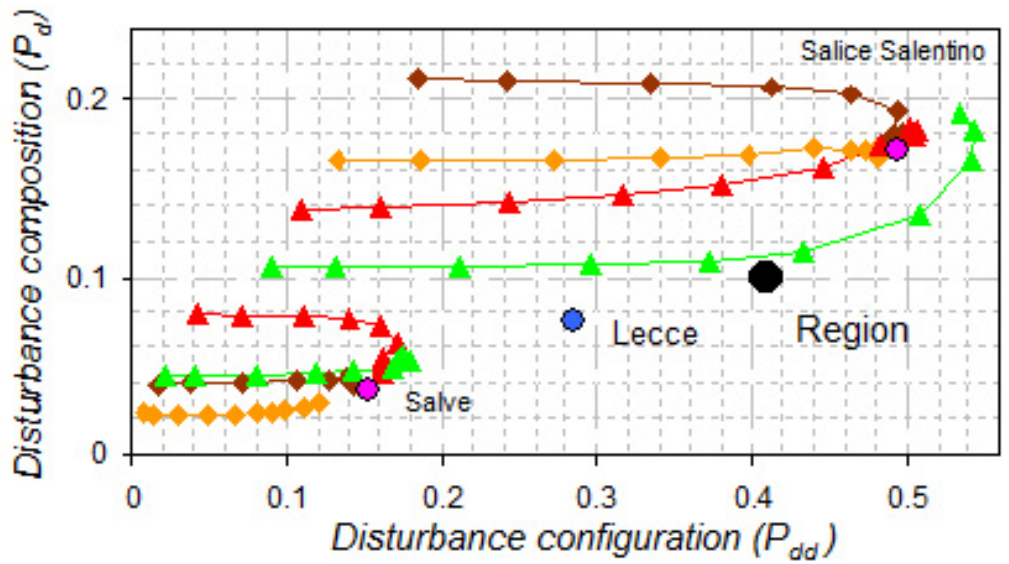

\section{Within and cross-scale comparisons of social- ecological landscape convergence points}

The location of the convergence point $(\mathrm{CP})$ of any SEL in the same $\left[P_{d}, P_{d d}\right]$ space is a measure of intensity of the disturbance pattern over the entire SEL. Were disturbance composition $\left(P_{d}\right)$ or configuration $\left(P_{d d}\right)$ distributed spatially at random among subsystems in the panarchy, $\mathrm{CP}$ values would be correspondingly similar to that of the entire region and among different subsystems, otherwise land-use composition and relative disturbance of subsystems would be responsible for the deviations observed.

All log-odds for both composition and configuration are significantly different (Table 2), thus disturbance composition $\left(P_{d}\right)$ and configuration $\left(P_{d d}\right)$ are not distributed randomly among provinces but rather there is a geographical pattern of disturbance among provinces with some subsystems contributing, more or less, disproportionately to the regional $\mathrm{CP}$. Among provinces, Bari has the smallest negative log-odds in the region as regards 
composition, whereas Lecce has the smallest negative log-odds in the region as regards configuration (Table 2). Therefore, Bari generally acts as a sink and Lecce has a disturbance much less clumped than the region overall (Fig. 4). Foggia has the highest positive log-odds for both composition and configuration with reference to the region, meaning that it acts as a disturbance source, with disturbance greater and much more clumped than the average in the region. Log-odds for counties are again significantly different (Table 2). Salice Salentino has the highest positive log-odds (source) with reference to its province (Lecce), whereas Salve has the smallest negative log-odds (sink) with reference to the same province.

\section{Simulated neutral landscape pattern}

Results on simulated neutral landscape patterns are given in detail in the Appendix. As expected for a random pattern, every place on the random map experiences the same disturbance pattern for a sufficiently large window, thus the random map exhibits a convergence to the $\mathrm{CP}$ at a relatively small window size (Fig. A2). The random pattern exhibits an almost even distribution of pixels among clusters, and simulated CPs at various $P_{d}$ values are always located above the main diagonal of $\left[P_{d}, P_{\mathrm{dd}}\right]$ (Fig. A2, insert). The other real and simulated maps do not exhibit such an early convergence with increasing window size, which generally indicates non-random multi-scale trajectories, nor is there an even distribution of pixels among clusters, and no $\mathrm{CP}$ is ever found above the diagonal of pattern metric space $\left[P_{d}, P_{\mathrm{dd}}\right]$ (Figs $\left.2, \mathrm{~A} 3, \mathrm{~A} 4\right)$. Multifractal maps exhibit the slowest convergence and none of the trajectories reaches the $\mathrm{CP}$, whereas the hierarchical maps do exhibit a convergence for window sizes larger than for the random map (Figs A3, A4).

The trajectories of hierarchical maps look like strings of a frayed rope that start from different regions at local scales and then quickly aggregate along the scale to form a common rope given by variations in disturbance composition but with configuration almost constant showing a remarkable cross-scale mismatch (Fig. A4). Cluster trajectories appear as strings that approach the rope from different regions and join the rope at different levels of composition with high cross-scale increments of configuration. For multifractal maps, cluster trajectories do not show any convergence to a common rope because, by definition, a multifractal is constructed to have the higher moments grow increasingly with scale, making for nonstationary parameters, which implies that cluster strings will not converge to a rope except asymptotically.

\section{DISCUSSION}

Overall, results not only agree with what we know about the complex patterns of land-use dynamics in Apulia, but they also provide a novel insight into the disturbance heterogeneity of social-ecological landscapes (SELs) in the region. We used a single pattern metric space $\left[P_{d}, P_{d d}\right]$ with the embedded convergence point (CP) for standardizing comparisons among disturbance cluster trajectories and land-use disturbance trajectories of the diverse SELs in the panarchy. Trajectories of land-use disturbance located near the lower left hand corner (e.g., Fig. 3) show a minor spread in the $\left[P_{d}, P_{d d}\right]$ space in comparison to trajectories of real or simulated disturbance clusters (e.g., Figs 2, A2, A3, A4), and a different disturbance configuration along with a certain invariance of disturbance composition across scales. It has already been mentioned that Apulia is mainly affected by low disturbance levels overall. So, while disturbance cluster trajectories emphasize differences among locations in multiscale composition and pattern, by confining, for instance, extreme highly disturbed locations in clusters like C8 and C7 (5.8\%-8.8\%) (Fig. 2), landuse disturbance trajectories gather various situations of disturbance composition, which must necessarily reflect the most recurrent low disturbance level of the region (Fig. 3).

Land uses are not the only factor determining disturbance cluster trajectories, and there is no compelling evidence of a high correlation between land use and disturbance trajectory (Zurlini et al. 2006,; 2007). The exceptions are natural parks, forests and olive groves contributing most of $\mathrm{C}$, and intensive agricultural land contributing most of C8 (Fig. 2). Prevailing land uses contribute in different ways to the disturbance gradient at multiple scales for different SELs, as land uses resulted from other types of biophysical and social controls shaping the region. Disturbance processes and frequencies at work are not always the same for the same land use, but rather they are linked to both the nature and composition of SEL mosaics and the different management practices of the same land use (Figs 3, 4, and 5). 
Table 2. Disturbance composition $\mathrm{P}_{\mathrm{d}}$ and configuration $\mathrm{P}_{\mathrm{dd}}$ values defining convergence points (CPs) of SELs like provinces and counties in the panarchy of Apulia (Fig. 1) with regional $P_{d}=0.10$. Log-odds ratios and approximate confidence limits are given for $\mathrm{P}_{\mathrm{d}}$ and $\mathrm{P}_{\mathrm{dd}}$. Log-odds ratios for provinces refer to the regional $\mathrm{CP}$, whereas log-odds ratios for counties refer to the $\mathrm{CP}$ of Lecce province (see text).

\begin{tabular}{lrrrrrr}
\hline \hline $\begin{array}{l}\text { SELs in the nested } \\
\text { panarchy }\end{array}$ & \multicolumn{3}{c}{$\boldsymbol{P}_{d}$} & & \multicolumn{3}{c}{$\boldsymbol{P}_{d d}$} \\
\hline Bari & Odds ratio & log-odds ratio & Conf. Limits & Odds ratio log-odds ratio & Conf. Limits $^{\S}$ \\
Brindisi & 0.564 & -0.572 & {$[-0.576 ;-0.568]$} & 0.707 & -0.347 & {$[-0.352 ;-0.343]$} \\
Foggia & 0.615 & -0.486 & {$[-0.491 ;-0.480]$} & 0.691 & -0.370 & {$[-0.377 ;-0.363]$} \\
Lecce & 1.638 & 0.494 & {$[0.491 ; 0.496]$} & 1.355 & 0.303 & {$[0.301 ; 0.306]$} \\
Taranto & 0.719 & -0.330 & {$[-0.334 ;-0.325]$} & 0.564 & -0.572 & {$[-0.578 ;-0.567]$} \\
& 0.836 & -0.179 & {$[-0.184 ;-0.175]$} & 0.817 & -0.202 & {$[-0.207 ;-0.197]$} \\
Salve & 0.467 & -0.761 & {$[-0.818 ;-0.704]$} & 0.453 & -0.791 & {$[-0.876 ;-0.707]$} \\
Salice salentino & 2.581 & 0.948 & {$[0.927 ; 0.969]$} & 2.449 & 0.896 & {$[0.872 ; 0.919]$}
\end{tabular}

$\S$ Approximate $95 \%$ confidence limits for the log-odds ratios

Comparisons of real and simulated disturbance patterns derived by clustering indicate that disturbances at multiple scales for the region are not random, but might exhibit a mixture of hierarchical and multifractal patterns although they look very similar to multifractal (Figs 2, A2, A3, A4). The mixture of hierarchical and multifractal patterns from clustering appears to be related to the interplay of disturbance patterns linked to specific land uses (Zurlini et al. 2007).

The geographical pattern of disturbance among provincial SELs is confirmed by log-odds ratios (Table 2). The interplay among land-use disturbance trajectories suggest roles, i.e., source or sink, played across scales by different SELs and land uses in the panarchy as to the potential spread of disturbance agents to neighboring areas. Land uses in SELs show distinct disturbance trajectories at multiple scales with paths mostly aligned up to the $\mathrm{CP}$ value of the entire region, and with increasing disturbance composition generally ranging from natural areas to arable land. Arable land plays mainly a role of source (Figs 3 and 4), whereas natural areas and permanent cultivations, given by olive groves or vineyards, a role of sink. The mismatch in role, e.g. between arable land (source) and natural areas (sink), is not the same across scales, which would imply a certain parallelism between dashed lines in Fig. 3. The way disturbance configuration increases with scale is more pronounced for arable lands at the regional level (e. g., Fig. 3) due to intensification of agriculture by which fields have been merged and enlarged to enhance farming efficiency, resulting in almost homogeneously farmed landscapes (e.g., Foggia, Fig. 1). Interestingly, some land uses can also apparently change their role from source to sink across scales as they do in Brindisi (Fig. 4). In this case, scale mismatch occurs because in this province natural areas are perforated at local scale by a number of heterogeneous agricultural cultivations.

Because disturbances may be inflicted at multiple scales, both native and invasive species as well as habitats could be differentially affected by disturbance in the same place on different scales, and to look at how disturbances are patterned in 
space at multiple scales is a potentially useful way to appreciate these differences. Fragmentation of remaining natural habitat due to expanded agriculture is a major cause of extinction of fragmented, small and isolated populations (Tilman et al. 2002, Benton et al. 2003), on the other hand, habitat patches connected by corridors retain more native plant species than do isolated patches supporting the use of corridors in biodiversity conservation (Damschen et al 2006). As to invasive species, percolation theory (Stauffer 1985) indicates that the critical level of disturbance at which invasive spread occurs on random maps is $P_{d}$ $\geq 0.59$, and the effective region in $\left[P_{d}, P_{d d}\right]$ space is defined by the portion of a cluster or land use trajectory that lies above that threshold level (Figs 2, A2, A3, A4). Invasive spread occurring at lower levels of disturbance, when disturbances are large or clumped in distribution on the landscape (With 2004), corresponds to portions of trajectories with very high $P_{d d}$ values in $\left[P_{d}, P_{d d}\right]$ space (e.g., Fig. 2). This is particularly central to the dispersal of alien species and therefore to the spatial distribution of risk of competition from alien species. Ideally, poor dispersers could spread more in landscapes in which disturbances are concentrated in space (contagious disturbance), whereas good dispersers could spread more in landscapes where disturbances are small and dispersed, i.e., fragmented disturbance (With 2004). In the rope area of a hierarchical pattern of disturbance (e.g., Fig. A4) different disturbance clusters aggregate into a large geographic region where invasive species might experience, for a specific scale range of disturbance composition, a large undisturbed matrix perforated by patches of disturbance with the same configuration.

Although agricultural landscapes are often considered homogenous matrices, in practice there is a large heterogeneity in farming systems, as well as in land-use management practices. Compared to rather homogeneous and highly contagious inputintensive systems like broad agricultural areas (e.g., Foggia, Fig. 1), less contagious heterogeneous rural landscapes (e.g., Lecce, Fig. 1) tend to include more plant species in the seed rain and create marginal effects (Harris 1988). Seed-eating birds, particularly those dependent on cereal grain or annual weed seeds, occur in higher numbers in pastoral areas containing small areas of arable land occurring in pure grassland landscapes (Robinson and Sutherland 2002), the diversity of generalist insects in crops increases with habitat diversity (Jonsen and Fahrig 1997), and habitat diversity enables source populations to repeatedly seed sink populations within intensively managed fields (Sunderland and Samu 2000).

Holling et al. (1996) suggested that contagious disturbance processes are examples of keystone processes producing discrete ecological patterns. In our examples, typical contagious disturbance processes are related to land use or land cover and reflect changes associated with agricultural expansion and intensification, land conversion, farming practices and urban sprawl. Unlike other disturbances such as storms or hurricanes, the extent and duration of contagious disturbance events in Apulia are dynamically determined by the interaction of the disturbance with the landscape configuration. Although land-use intensification is addressed here as source of disturbances, agriculture is not always detrimental to biodiversity, since the high nutrient status of the ecosystem can occasionally enhance the biodiversity of a variety of organisms (e.g., Tscharntke et al. 2005).

\section{CONCLUDING REMARKS}

This study clarifies the potential roles of natural areas and permanent cultivations (olive groves and vineyards) in buffering landscape dynamics and disturbances across scales in South Italy. Their function has consequences for regional biodiversity management since their particular interactions in space and time may govern if and how disturbances associated with land-use intensification (sources) will trigger changes affecting regional biodiversity. Taking into account the footprint of agriculture (Butler et al. 2007), disturbance sources and sinks could be properly arranged deliberately by planners and managers in the landscape to match some desirable spatial and temporal pattern so that ecological disruptions only occur across a limited range of scales, which would allow persistence of ecological functions operating on unaffected scales. These considerations are similar to those involved in assessing the risk of invasive spread across fragmented landscapes (With 2004), which requires consideration of the effects of landscape structures and scales on processes like land-use intensification contributing to invasive spread with successful colonization.

In summary, we show that in the real geographic world, spatial scale mismatches of disturbance can occur at particular scale ranges because of cross- 
scale disparities in land uses for the amount of disturbance and/or the lag distance of disturbance configuration, leading to more or less exacerbation of contrasting source/sink systems along certain scale domains. All cross-scale source/sink issues can produce both negative and positive effects on the scales above and below their levels, i.e., crossscale effects. The challenge then, is to develop adaptive management strategies for socialecological landscapes (SELs) with social norms that foster cooperative responses across scales and jurisdictional levels to enhance the benefits and minimize the negative effects (e.g., Folke et al. 2005, Levin 2006). Because stakeholders are facing complex and uncertain management situations, they have to learn about their social-ecological environment in order to act in more sustainable ways. Public participation resulting in social learning processes can create the conditions for these changes to happen (Steyaert and Ollivier 2007). This is not an easy matter, but at least, through the framework outlined in our examples, managers, as well as stakeholders belonging to SELs in the panarchy, can be aware of specific scale ranges of disturbance where mismatches might occur and that will help them to understand where and how to intervene in the panarchy of SELs to enhance long-term sustainability.

Responses to this article can be read online at: http://www.ecologyandsociety.org/vol13/iss 1/art26/responses/

\section{Acknowledgments:}

Anonymous referees are gratefully acknowledged for helpful comments on early drafts of the paper. Thanks to Bruce Milne for advice on the interpretation of neutral multifractal models.

\section{LITERATURE CITED}

Agresti, A. 1996. An Introduction to Categorical Data Analysis, Wiley and Sons, New York, New York, USA.

Alcamo, J., and E. M. Bennett. 2003. Ecosystems and human well-being. Millennium Ecosystem Assessment (MA). Island Press, Washington, D.C., USA.
Agenzia per la protezione dell'ambiente e per i servizi tecnici (APAT). 2005. La realizzazione in Italia del progetto europeo Corine Land Cover 2000. Technical report Number 36, Rome. Available online at: http://www.sinanet.apat.it.

Barnes, W. L., X. Xiong, and V. V. Salomonson. 2003. Status of terra MODIS and aqua MODIS. Advances in Space Research 32(11):2099-2106.

Benton, T. G., J. A. Vickery, and J. D. Wilson. 2003. Farmland biodiversity:is habitat heterogeneity the key? Trends in Ecology and Evolution 18: $182-188$.

Berkes, F., and C. Folke, editors. 1998. Linking social and ecological systems: management practices and social mechanisms for building resilience. Cambridge University Press. Cambridge, UK.

Butler, S. J., J. A. Vickery, and K. Norris. 2007. Farmland biodiversity and the footprint of agriculture. Science 315:381-384.

Carpenter, S. R., and M. G. Turner. 2001. Editorial. Panarchy 101. Ecosystems 4:389.

Cash, D. W., W. Adger, F. Berkes, P. Garden, L. Lebel, P. Olsson, L. Pritchard, and O. Young. 2006. Scale and cross-scale dynamics:governance and information in a multilevel world. Ecology and Society 11(2):8. [online] URL: http://www.ecology andsociety.org/vol11/iss2/art8/.

Chavez, P. S., Jr. 1988. An improved dark-object subtraction technique for atmospheric scattering correction of multispectral data. Remote Sensing of Environment 24:459-479.

Commission of the European Communities (CEC). 1999. Agriculture, environment, rural development: facts and figures. Office for Official Publications of the European Communities, Luxembourg.

Damschen, E. I., N. M. Haddad, J. L. Orrock, J. J. Tewksbury, and J. D. Levey. 2006. Corridors increase plant species richness at large scales. Science 313(5791):1284-1286.

Donald, R. F., R. E. Green, and M. F. Heath. 2001. Agricultural intensification and the collapse of Europe's farmland bird populations. Proceedings of the Royal Society, London B 268:25-29. 
Folke, C., T. Hahn, P. Olsson, and J. Norberg. 2005. Adaptive governance of social-ecological systems. Annual Review of Environment and Resources 30:441-473.

Fortin, M-J., B Boots, F. Csillag, and T.K. Remmel. 2003. On the role of spatial stochastic models in understanding landscape indices. Oikos 102:203-212.

Gardner, R. H. 1999. RULE: Map generation and a spatial analysis program. Pages 43-62 in J. M. Klopatek and R. H. Gardner, editors. Landscape ecological analysis issues and applications. Springer, New York, New York, USA.

Gardner, R. H., B. T. Milne, M. G. Turner, and R. V. O'Neill. 1987. Neutral models for the analysis of broad-scale landscape pattern. Landscape Ecology 1:19-28.

Goward, S. N., B. Markham, D. Dye, W. Dulaney, and J. Yang. 1991. Normalized difference vegetation index measurements from the Advanced Very High Resolution Radiometer. Remote Sensing of Environment 35:257-277.

Gunderson, L H., and C. S. Holling, editors. 2002. Panarchy: understanding transformations in human and natural systems. Island Press, Washington, D. C., USA.

Hails, R. S. 2002. Assessing the risks associated with new agricultural practices. Nature 418:685-688.

Harris, L. D. 1988. Edge effects and conservation of biotic diversity. Conservation Biology 2:330-332.

Holling, C. S., G. Peterson, P. Marples, J. Sendzimir, K. Redford, L. Gunderson, and D. Lambert. 1996. Self-organization in ecosystems: lumpy geometries, periodicities, and morphologies. Pages 346-384 in B. H. Walker and W. L. Steffen, editors. Global change and terrestrial ecosystems. Cambridge University Press, Cambridge, UK.

Jonsen, I. D., and L. Fahrig. 1997. Response of generalist and specialist insect herbivores to landscape spatial structure. Landscape Ecology 12:185-197.
Kennedy, T. A., S. Naeem, K. M. Howe, J. M. H. Knops, D. Tilman, and P. Reich. 2002. Biodiversity as a barrier to ecological invasion. Nature 417:636-638.

Kerkhoff, A. J., B. T. Milne, and D. S. Maehr. 2000. Toward a panther-centered view of the forests of South Florida. Conservation Ecology 4(1):1. [online] URL: http://www.consecol.org/vol4/iss1/art1/

Lavorel, S., R. H. Gardner, and R. V. O'Neill. 1993. Analysis of patterns in hierarchically structured landscapes. Oikos 67:521-528.

Legendre, P., and L. Legendre. 1998. Numerical Ecology. Second English edition. Elsevier Science BV, Amsterdam, The Netherlands.

Levin, S. A. 2006. Learning to live in a global commons:socioeconomic challenges for a sustainable environment. Ecological Research 21:328-333.

Levins, R. 1969. Some demographic and genetic consequences of environmental heterogeneity for biological control. Bulletin of the Entomology Society of America 71:237-240.

Li, H., and J. F. Reynolds. 1994. A simulation experiment to quantify spatial heterogeneity in categorical maps. Ecology 75:2446-2455.

Loreau, M., and A. Hector. 2001. Partitioning selection and complementarity in biodiversity experiments. Nature 412:72-76.

Matson, P. A., W. J. Parton, A. G. Power, and M. J. Swift. 1997. Agricultural intensification and ecosystem properties. Science 277:504-509.

Milne, B. T. 1992. Spatial aggregation and neutral models in fractal landscapes. American Naturalist 139:32-57.

Mitchell, R. J., M. A. Sutton, A. M. Truscott, I. D. Leith, J. N. Cape, C. E. R. Pitcairn, and N. van Dijk. 2004. Growth and tissue nitrogen of epiphytic Atlantic bryophytes:effects of increased and decreased atmospheric $\mathrm{N}$ deposition. Functional Ecology 18:322-329.

National Aeronautics and Space Administration (NASA). 2007. MODIS 32-day composite 
MOD44C, Collection 3. The Global Land Cover Facility, University of Maryland, College Park, Maryland, USA. Available online at: http://glcf.um iacs.umd.edu/data/modis/.

O'Neill, R. V., R. H. Gardner, and M. G. Turner. 1992. A hierarchical neutral model for landscape analysis. Landscape Ecology 7:55-61.

Parmesan, C., and G. A. Yohe. 2003. Globally coherent fingerprint of climate change impacts across natural systems. Nature 421:37-42.

Peterjohn, W. T., and D. L. Correll. 1984. Nutrient dynamics in an agricultural watershed. Observations on the roles of a riparian forest. Ecology 65:1466-1475.

Pickett, S. T. A., and P. S. White, editors. 1985. The ecology of natural disturbance and patch dynamics. Academic Press, Orlando, Florida, USA.

Reidsma, P., T. Tekelenburg, M. van den Berg, and R. Alkemade. 2006. Impacts of land-use change on biodiversity:An assessment of agricultural biodiversity in the European Union. Agriculture, Ecosystems and Environment 114:86-102.

Ricketts, T. H. 2001. The matrix matters: effective isolation in fragmented landscapes. American Naturalist 158:87-99.

Riitters, K. H., O'Neill, R. V., Hunsaker, C. T., Wickham, J. D., Yankee, D. H., Timmins, S., Jones, K. B., and B. L. Jackson. 1995. A factor analysis of landscape pattern and structure metrics. Landscape Ecology 10:23-39.

Riitters, K. H., J. D. Wickham, R. V. O'Neill, K. B. Jones, and E. R. Smith. 2000. Global-scale patterns of forest fragmentation. Conservation Ecology 4(3). [online] URL: http://www.ecologyan dsociety.org/vol4/iss2/art3/.

Robinson, R. A., and W. J. Sutherland. 2002. Post-war changes in arable farming and biodiversity in Great Britain. Journal of Applied Ecology 39:157-176.

Stauffer, D., editor. 1985. Introduction to percolation theory. Taylor and Francis, Philadelphia, Pennsylvania, USA.

Steyaert, P., and G. Ollivier. 2007. The European Water Framework Directive: how ecological assumptions frame technical and social change. Ecology and Society 12(1):25. [online] URL: http:/ /www.ecologyandsociety.org/vol12/iss1/art25/.

Stokstad, E. 2006. Pollinator diversity declining in Europe. Science 313(5785):286.

Sunderland, K., and F. Samu. 2000. Effects of agricultural diversification on the abundance, distribution, and pest control potential of spiders: a review. Entomologia Experimentalis et Applicata 95:1-13.

Tilman, D., K. G. Cassman, P. A. Matson, R. Naylor, and S. Polasky. 2002. Agricultural sustainability and intensive production practices. Nature 418:671-677.

Tscharntke T, A. M. Klein, A. Kruess, I. SteffanDewenter, and C. Thies. 2005. Landscape perspectives on agricultural intensification and biodiversity: ecosystem service management. Ecology Letters 8:857-874.

Turner, M. G., and R. H. Gardner, editors. 1991. Quantitative methods in landscape ecology. Springer-Verlag, New York, New York, USA.

Tylianakis, J. M., R. K. Didham, and S. D. Wratten. 2004. Improved fitness of aphid parasitoids receiving resource subsidies. Ecology 85:658-666.

Vickery, J. A., J. R. Tallowin, R. E. Feber, E. J. Asteraki, P. W. Atkinson, R. J. Fuller, and V. K. Brown. 2001. The management of lowland neutral grasslands in Britain: effects of agricultural practices on birds and their food resources. Journal of Applied Ecology 38:647-664.

Viel, M., and G. Zurlini, editors. 1986. Indagine ambientale del sistema marino costiero della regione Puglia. Elementi per la definizione del piano delle coste. ENEA, Direzione Centrale Relazioni, Rome, Italy.

Vitousek, P. M., J. Aber, R. W. Howarth, E. G. Likens, P. A. Matson, D. W. Schindler, W. H. Schlesinger, and D. Tilman. 1997. Human alteration of the global nitrogen cycle:causes and consequences. Ecological Applications 7:737-750.

Walther, G.-R., E. Post, P. Convey, A. Menzel, C. Parmesan, T. J. C. Beebee, J.-M. Fromentin, O. Hoegh-Guldberg, and F. Bairlein. 2002. 
Ecological responses to recent climate change. Nature 416:389-395.

With, K. A. 2002. The landscape ecology of invasive spread. Conservation Biology 16:1192-1203.

With, K. A. 2004. Assessing the risk of invasive spread in fragmented landscapes. Risk Analysis 24:803-815.

Young, S. S., and R. Harris. 2005. Changing patterns of global-scale vegetation photosynthesis, 1982-1999. International Journal of Remote Sensing 26(20):4537-63.

Zurlini, G., K. H. Riitters, N. Zaccarelli, and I. Petrosillo. 2007. Patterns of disturbance at multiple scales in real and simulated landscapes. Landscape Ecology 22:705-721.

Zurlini, G., K. H. Riitters, N. Zaccarelli, I. Petrosillo, K. B. Jones, and L. Rossi. 2006. Disturbance patterns in a socioecological system at multiple scales. Ecological Complexity 3:119-128. 
Appendix 1. Satellite imagery and processing, normalized difference vegetation index (NDVI), change detection, moving windows and neutral landscape models.

Please click here to download file 'appendix1.pdf'. 